Revista Iberoamericana. Vol. LXV, Núms. 188-189, Julio-Diciembre 1999; 633-647

\title{
CUERPO Y RAZA: EL CICLO DE LA IDENTIDAD NEGRA EN LA LITERATURA PUERTORRIQUEÑA
}

\author{
POR \\ Zaira O. Rivera Casellas \\ Wesleyan University
}

La teoría del cuerpo se presta para la interpretación de imágenes, símbolos y representaciones que definen un ciclo de la identidad negra en la tradición literaria puertorriqueña. ${ }^{1}$ Es la noción de un "cuerpo imaginario", ${ }^{2}$ que al personificar un sujeto diferenciado racialmente, mantiene reciprocidad histórica con la evolución del nacionalismo cultural y la represión racial en el siglo XX. El proceso de "formación racial"3 en Puerto Rico enlaza las tradiciones culturales y las estrategias políticas a una manipulación paradójica del cuerpo negro. En la literatura, El tuntún de pasa y grifería (1937) es la primera expresión cultural que idealiza el cuerpo negro y mulato como la inscripción categórica para cuestionar las consecuencias políticas del capitalismo y el colonialismo. A partir de la publicación del Tuntún, la experiencia ontológica de la opresión, la marginación social, la resistencia antihegemónica se localiza en el espacio cultural prefigurado por la

\footnotetext{
${ }^{1}$ La teoría del cuerpo, según la han conceptualizado Judith Butler (Bodies that Matter: on the Discursive Limits of 'Sex'), Moira Gatens (Imaginary Bodies: Ethic, Power and Corporeality) y Elizabeth Grosz (Volatile Bodies: Toward a Corporeal Feminism), se ha limitado al análisis de las imágenes, los símbolos y las representaciones del cuerpo femenino. Tanto Butler como Grosz y Gatens se han basado en la perspectiva psicoanalítica para interpretar las concepciones metafísicas que forjan las prácticas culturales, políticas y sociales a partir del cuerpo femenino. En este ensayo, la concepción teórica del cuerpo está complementada con la especificidad cultural, política y social de la clasificación racial.

${ }^{2}$ Moira Gatens define el "cuerpo imaginario" así: "An imaginary body is not simply a product of subjective imagination, fantasy or folklore. The term 'imaginary' will be used in a loose but nevertheless technical sense to refer to those images, symbols, metaphors and representations which help construct various forms of subjectivity. In this sense, I am concerned with the (often unconsious) imaginaries of a specific culture: those ready-made images and symbols through which we make sense of social bodies and which determine, in part, their value, their status and what will be deemed their appropriate treatment" (xviii).

${ }^{3}$ Michael Omi y Howard Winant definen el proceso de formación racial: " $[\ldots]$ as the sociohistorical process by which racial categories are created, inhabited, transformed, and destroyed. Our attempt to elaborate a theory of racial formation will proceed in two steps. First, we argue that racial formation is a process of historical situated projects in which human bodies and social structures are represented and organized. Next we link racial formation to the evolution of hegemony, the way in which society is organized and ruled [...] From a racial formation perspective, race is a matter of both social structures and cultural representations" (55-56).
} 
población afropuertorriqueña. En ese sentido, la elaboración estética del cuerpo negro revela las vicisitudes de una tradición racial que expresa la transformación, la fijación, la repetición y el destino del racismo, además de la explotación y la alienación política. El carácter fundacional del Tuntún, orienta la literatura nacional hacia la búsqueda de un pasado racial que enmiende las frustaciones políticas y sociales del presente. La codificación de esos principios estéticos informa la evolución de un proceso de formación racial, en el cual el cuerpo negro corrobora la manipulación de los símbolos culturales en el espacio político y la historia nacional. La relación de domesticación y resistencia que materializa la abstracción corporal de la identidad afropuertorriqueña, a partir de la poética palesiana, articula la dinámica de una narrativa racial centrada en la historicidad del cuerpo negro.

\section{EL TUNTÚN DE PASA Y GRIFERIA: LA LECTURA MODERNA DEL CIMARRONAJE}

La innovación del mundo poético de Palés recrea utópicamente el ambiente social de las comunidades de los negros libres como el espacio donde se asume una conciencia cimarrona. De ese modo el poeta relativiza la situación colonial bajo el dominio norteamericano dentro de una experiencia racial, y se acerca al cuestionamiento de los imperativos de su momento histórico. Al igual que otros escritores caribeños, Palés concibe un gesto de vanguardia artística centrado en la toma de conciencia de la modernidad racial. Simon Gikandi, refiriéndose a los escritores del Caribe angloparlante, describe ese proceso así: "Caribbean writers, in response to their historical marginalization, have evolved a discourse of alterity which is predicated on a deliberate act of self-displacement from the hegemonic culture and its central tenets. The Maroon is the most visible symbol of this gesture of cultural "dedoublement"” (20). En el "desdoblamiento" de la personalidad cimarrona, la representación de la cultura afropuertorriqueña consolida una base física entre identidad, resistencia y rebelión mediante la idealización de un pasado africano, la invocación a la esencia negra y el heroísmo de la lucha esclavista. Son las estrategias poéticas para negar la americanización cultural y económica impuestas por los actos imperialistas y el monopolio azucarero de los años treinta. Al exacerbar la conducta y la cultura de un grupo racial excluido de los procesos históricos y censurado en su idiosincrasia individual, Palés deliberadamente disloca la noción totalizadora del capitalismo alienante. En ese sentido, la tradición racial en la poesía afroantillana de Palés connota entereza, homogeneidad, continuidad histórica, y sobre todo, "aspira a expresar la conciencia colectiva puertorriqueña y antillana, [además de] su disposición de vida" (Díaz Quiñones 79).

La metáfora vitalizante del cuerpo negro y mulato, por ejemplo de Tembandumba de la Quimbamba y la Mulata-Antilla, confronta irónicamente la cultura dominante por medio de una relación no técnica con el universo. La recreación de una existencia negra, privada de escapar del cuerpo, factor que determina su subordinación histórica y social, construye imágenes corporales que ambicionan forjar un sentido de unidad y fortaleza espiritual ante la ansiedad colonial. Esto último, Rubén Ríos Avila lo plantea así:

fundar una poética de lo negro, como puede verse en el Tuntún equivale, de cierta forma, a fundar una poética del cuerpo. Lo interesante es ver cómo ese orden heredado, ese 
prejuicio adquirido se transforma en un instrumento de movilización retórica y, en última instancia, ideológica, en Palés. Ese cuerpo que el orden burgués define para el negro termina convirtiéndose en el instrumento de agresión para derrumbar la primacía de un mundo vertebrado alrededor del alma y del conocimiento entendido como abstracción, como trascendencia del cuerpo (566).

El reclamo ideológico que legitimiza el Tuntún como producción cultural, moviliza un antagonismo constitutivo de la personalidad nacional mediante la mímesis ininteligible de una representación corporal. La exterioridad física en la cual se configura la identidad racial subraya el poder de la palabra poética para materializar un cuerpo distanciado de su vínculo temporal con el espacio político. El Tuntún es un acto poético unificado que reúne diferentes respuestas al colonialismo y a su vez concilia estrategias literarias disidentes. Pero más importante aún, las repercusiones del argumento nacional planteado por la producción poética de Palés no solo marcan una escisión dentro de la tradición literaria del costumbrismo jíbaro, sino que también plantean una contradicción intrínseca del pensamiento nacional: la represión interna del racismo.

\section{El CUERPO NEGRO VISTO DESDE ARRIBA}

Desde los años treinta, el acalorado debate entre Luis Antonio Miranda, J.I. de Diego Padró y Gracian y Miranda Archilla sobre el Tuntún inicia una polémica contenciosa sobre la posiblidad de definir racialmente la identidad nacional. Arcadio Díaz Quiñones señala en su ensayo sobre la poesía de Palés, incluido en El almuerzo en la hierba (1982) que desde la publicación del Tuntún, la crítica coincide en una interpretación de la poesía afroantillana definida por el exotismo, el primitivismo, el romanticismo o la evasión (77). Esa ambivalencia crítica apunta, por un lado, a la polarización del análisis cultural entre civilización y barbarie (77), según lo demuestra Díaz Quiñones, pero por otro lado, describe la brecha que subsiste entre las prácticas culturales y los objetivos políticos, debido a la falta de uniformidad del sistema nacional con respecto a la cuestión de la diversificación de las manifestaciones sociales. De hecho, más adelante en la historia literaria puertorriqueña, los eventos y las estrategias políticas de los años cincuenta confirman la tensión provocada por los esfuezos de colectivización cultural orientados a eliminar la ambiguedad creada por la exclusividad de identidades raciales. La urgencia populista del momento político promueve la revisión de los símbolos y las expresiones culturales que conforman el imaginario nacional. En ese inventario de los signos y las representaciones asociadas a la identidad cultural de la nación, el Tuntún exige una relectura que se ajuste al imperativo conciliador de la agenda modernizadora.

En el ambiente cultural y literario prevalece una sensación de ambigüedad ante el alcance de los nuevos planteamientos políticos y el mejoramiento de las condiciones de vida. Al mismo tiempo, se percibe una fuerte represión contra el movimiento nacionalista. Entre la elite intelectual impera la estrategia de clausurar espacios de significación demarcados por el voluntarismo radical. El solipsismo racial, al cual apelaba el Tuntún para defender la amenaza imperialista en los años treinta, pasa a ser reevaluado a la luz del nuevo momento histórico. Las revisiones que hace Margot Arce a su opinión sobre el Tuntún, 
ilustran el nuevo ciclo al cual se amolda la polémica racial en la centralización del poder político y la formulación del desarrollismo industrial. En el ensayo, "'Negar lo negro sería gazmoñería': Luis Palés Matos, Margot Arce, and the Black Poetry Debate", Magali Roy Fequiere examina cómo la opinión de Margot Arce sobre la territorialización del carácter nacional en la experiencia de la cultura negra sufre la represión de la autocensura, para acogerse a las demandas políticas y culturales de la década del cincuenta. De acuerdo a Roy Fequiere, las modificaciones hechas por Margot Arce en 1950 a su ensayo de 1933, "Impresiones: notas puertorriqueñas", afirman la urgencia de objetivizar el referente social de la persona auténticamente negra dentro de la coyuntura histórica y social, para así neutralizar los reclamos culturales, políticos y económicos asociados al antagonismo de una identidad racial. El metódico distanciamiento del hecho histórico de la invasión norteamericana, la supresión de referencias al vanguardismo cultural de Palés dentro del movimiento del arte negro, según señala Roy Fequiere, eclipsan la caracterización de la personalidad negra en el argumento de Arce a la de "un negro teórico, hipotético, abstracto, que Palés ha visto y ha creado con datos de procedencia literaria" (86).

El acercamiento crítico de Arce a la obra de Palés trastoca la dimensión de la realidad social que había identificado en los años treinta, tanto al nivel personal del poeta como al nivel colectivo de la situación nacional. La canonización del proyecto palesiano según lo encaminaron los agudos análisis críticos de Arce en los años anteriores, en los años cincuenta en cambio se ajusta a la narración de otro "tiempo racial". ${ }^{4}$ Es decir, la inscripción fenotípica del cuerpo negro propulsada por la poesía afroantillana, como la distorsión histórica del progreso, pasa a otro lapso temporal dentro de las prácticas económicas y políticas del momento. De ese modo, la distinción racial se desconecta del control del cuerpo material para recrear nuevas inversiones en el capital simbólico de la cultura. La relación entre el lenguaje y el tiempo actual contenida en la abstracción del cuerpo negro es despojada socialmente de las propiedades, los significados y los valores que naturalizan la posición de un sector social dentro de las divisiones del mundo real.

Ahora bien, desde la perspectiva lacaniana, Judith Butler ha examinado las posibles articulaciones ideológicas que crean o renuevan las representaciones corporales de una identidad política en la jerarquía del orden simbólico, de la siguiente manera:

Political signifiers, especially those that designate subject positions, are not descriptive, that is, they do not represent pregiven constituencies, but are empty signs which come to bear phantasmatic investments of varios kinds [...] Paradoxically, the failure of such signifiers $[. .$.$] fully to describe the constituency they name is precisely what constitutes$ these signifiers as sites of phantasmatic investment and discursive rearticulations. It is what opens the signifier to new meanings and new possibilities for political resignification (191).

En los años cincuenta, la construcción ideológica que sucita dentro del debate racial la poesía afroantillana de Palés infiere una alusión falsa del carácter nacional. Lo que

\footnotetext{
${ }^{4}$ Para Howard Winant un tiempo racial implica: "[...] a racial longue durée in which the slow inscription of phenotypical signification took place upon the human body, in and through conquest and enslavement, to be sure, but also as an enormous act of expression, of narration" (21).
} 
persiste en el ambiente político es la búsqueda de una autenticidad común que proyecte la unidad de una sola nación puertorriqueña libre de exclusividades culturales y raciales. Sin embargo, en esa condensación de las categorías nacionales se revierte el "fantasma racial"; a una tensión interna debido a la prerrogativa de crear un sentido de validación consensual entre la comunidad nacional. Asimismo el afianzamiento de la creencia colectiva de una modernización política cancela las inversiones ideológicas de emancipación cultural y social asignadas al fantasma racial en los años treinta.

De manera similar, la perspectiva del tiempo permite a Jaime Benítez recontextualizar las ideas que expuso sobre la poesía negra de Palés en la década del treinta. En el pórtico a la edición del Tuntún de 1950 titulado, "Luis Palés Matos y el pesimismo en Puerto Rico: Doce años después", Jaime Benítez tiene la oportunidad de retocar ideológicamente los efectos culturales de la aportación artística de Palés dentro de la retórica del progreso que propulsa su participación en la centralización y la institucionalización de la formula política del muñocismo. En la conferencia que dictó en la Universidad de Puerto Rico en 1938, de acuerdo a Benítez su objeción inicial a la obra de Palés durante los años treinta era que: “[...] temía se difundiera entre nuestras clases cultas la actitud de requiem entre dolido y bachatero con que el poeta parecía oficiar sobre Puerto Rico [...] Mi conferencia venía a destacar a Palés como el gran poeta puertorriqueño y a advertir contra el pesimismo ambiental recogido en su obra" (10-11). Al igual que Tomás Blanco y Antonio S. Pedreira, Jaime Benítez adopta el argumento degenerativo del mulataje y el determinismo geográfico para desfigurar el carácter conflictivo de las relaciones raciales y sociales. De hecho, Benítez difiere "[d]el criterio de quienes ven en la poesía palesiana toda una metafísica racial" (28), ya que el mestizaje racial crea un impasse social que "[...] perjudica a todos espiritualmente" (36-37). La dramatización de la dinámica racial que expresa el Tuntún al nivel de una experiencia cotidiana, es según Benítez una forma de revocar la fundación fỉlosófica de una tradición nacional encaminada hacia el progreso.

La correspondencia ontológica del proyecto cultural del Tuntún difiere de la relación entre realidad y representación, sociedad y símbolo, que los miembros de la generación de Benítez quieren reclamar como parte de una "vasta reorientación espiritual [que] empieza a difundirse a fines del año 1938 y a partir de 1941 constituye gobierno por decisión y voluntad de los propios puertorriqueños" (10). En la deducción de Benítez sobre el carácter nacional, al igual que en el pensamiento clásico, el sacrificio corporal es la forma de asegurar una alianza entre la mente y la razón para garantizar la soberanía de un espíritu nacional. El reverso de ese mismo argumento sirve para sistematizar la exclusión de ciertos ciudadanos dentro de la organización política y social. Como señala Moira Gatens:

\footnotetext{
${ }^{5}$ Etienne Balibar explica este proceso así: "By seeking to circumscribe the common essence of nationals, racism thus inevitably becomes involved in the obsessional quest for a "core' of authenticity that cannot be found, shrinks the category of nationality and de-stabilizes the historical nation. This can lead, in an extreme case, to the reversal of the racial phantasm: since it is impossible to find racialnational purity and guarantee its provenance from the origins of the people, it becomes necessary to create it in conformity with the ideal of a (super-) national superman" (60-61).

'Este ensayo aparece reimpreso en la edición del Tuntún de pasa y grifería de Mercedes López-Baralt de 1993.
} 
At different times, different kinds of beings have been excluded from the [political] pact, often simply by virtue of their corporeal specificity. Slaves, foreigners, women, the conquered, children, the working classes have all been excluded from political participation, at one time or another, by their bodily specificity [...] Those who are not capable of the appropriate political forfeit are excluded from political and ethical relations. Rather they are defined by mere nature, mere corporeality and they have no place in the semi-divine political body except to serve it at its most basic and material level (24).

Igualmente en la década de los cincuenta, el aspecto metonímico y metafórico de la personalidad nacional representado por el cuerpo negro, es despojado de su autonomía ideológica y simbólica para legitimar un convenio dentro del imaginario nacional puertorriqueño.

Las reformulaciones de Margot Arce y Jaime Benítez sobre la aportación literaria de Palés, muestran cómo la retórica del orden y el progreso busca conciliar nuevas significaciones culturales y políticas de la identidad nacional. La actualización de sus opiniones responde a la censura que imponen las estructuras políticas y económicas, y que a su vez, se transforma en la autocensura de una producción intelectual que busca maximizar las fluctuaciones del capital cultural y simbólico en un momento de crisis. Tanto Arce como Benítez ponen énfasis en la objetividad crítica del Tuntún como estrategia para estabilizar la intuición de una práctica literaria, que fusiona exotismo y corporalidad para interrogar las prácticas de autoritarismo político y la agresión cultural. Así entonces, la representación del cuerpo negro se cristaliza como el fantasma de una etapa pre-moderna asociada a la incredulidad, al retraso y la desilusión del colectivo nacional.

\section{EL CUERPO NEGRO VISTO DESDE ABAJO}

A partir de los años cincuenta, el concepto cultura/raza se inserta en un ciclo de "reconversión cultural", término que utiliza Néstor García-Canclini para definir las secuencias y consecuencias que padecen las funciones y los significados de los sistemas simbólicos debido a los ciclos económicos modernizadores. En el caso particular de Puerto Rico, la transformación en la significación del paradigma racial corresponde, por un lado, a la transformación económica y social derivada de la industrialización, el urbanismo y la migración que promueve la centralización de la fórmula política del Estado Libre Asociado, y por otro lado, al radicalismo de los movimientos sociales que surgen en los Estados Unidos en contra de la segregación racial. El surgimiento de los movimientos raciales que comenzaron en los años cincuenta y sesenta transformaron profundamente la percepción y el significado de la subjetividad racial a nivel mundial. La noción de raza adquiere el status de un fenómeno público que altera la experiencia vivencial inmediata de los grupos sociales. De ese modo, el movimiento negro, con el apoyo de otros grupos minoritarios de fuera y dentro de los Estados Unidos, redefine el significado de la identidad racial como la rearticulación de un movimiento social capaz de modificar el orden social establecido (Omni; Winant 95-96).

En Puerto Rico, el impacto de la militancia racial expande la visión de los movimientos políticos y fortalece el sentimiento revolucionario. Del mismo modo, la solidaridad del 
movimiento independentista con la Revolución cubana, el marxismo y el feminismo incitan un reordenamiento ideológico de las esferas culturales. En la producción literaria de los años cincuenta, cuentos como "En el fondo del caño hay un negrito" (1954) de José Luis González, "Sol negro" (1958) de Emilio Díaz Valcárcel, "Aguinaldo negro" (1953) de Edwin Figueroa, entre otros, vigorizan una reinterpretación histórica y económica de la organización social basada en la exclusividad del argumento racial. En los años sesenta, en particular, se percibe cómo las diferentes reacciones críticas ante la dinámica racial están ligadas íntegramente a la expansión de la modernidad industrial y su repercusión en la socialización del mundo natural. En ese proceso de sustitución de estructuras y acontecimientos de la actividad humana, la naturaleza reflexiva del cuerpo humano se convierte en el locus de una autoidentidad que divulga mediante la "decadencia de la perversión sexual" las batallas, las victorias y las confrontaciones que obstruyen el acceso a la igualdad económica y social (Giddens 41).

El contenido ideológico de lo sexual halla en el acto contemplativo del cuerpo la manera de expresar una identidad negra que reactualice estados, vivencias, símbolos que den sentido a la fragmentación nacional. La correlación entre lo erótico, lo racial y lo sexual sobresale en la colección de cuentos de Luis Rafael Sánchez, En cuerpo de camisa (1966), como la estrategia estética a través de la cual la agresividad de los personajes negros deconstruye las metáforas inscritas en los cuerpos colonizados en tanto prototipos de una pasividad o docilidad social en el espacio cultural y político. En los relatos de Sánchez, "¡Jum!", "Tiene la noche una raíz", pero particularmente en "Aleluya negra", el erotismo textual transgrede el discurso oficial del progreso que había institucionalizado el Estado Libre Asociado desde 1952. En “¡Jum!" la agresión social de la comunidad contra el cuerpo homosexual del hijo de Trinidad, contradice el afeminamiento nacional que socava el argumento de René Marqués en "El puertorriqueño dócil" de 1960, para resaltar una oposición machista del carácter nacional contra la americanización (Lugo-Ortiz 117). En el cuento "Tiene la noche una raíz", la devaluación material del cuerpo y el espíritu de la prostituta negra, Gurdelia Grifitos, queda transpuesto hacia una instancia de amor y ternura maternal. Con la caracterización del homosexual y la prostituta se intercepta el abismo corrosivo de la sexualidad ligado al resquebrajamiento de las jerarquías sociales en el espacio marginal de la vida urbana. Por su parte, "Aleluya negra" invoca un erotismo totalizador mediante el cual la violencia sexual de los personajes, Carmelo el Retinto, "el negro más resabioso del palmar" (29), y Caridad, la "mulata tiznada" (28), complementan "esa 'fiereza' sexual que lo abarca todo: [el] cuerpo, [las] almas, [la] cultura, [la] economía [y la] política" (Cachán 185).

En cambio, para Isabelo Zenón, escritor clave en la desarticulación de la ficción de una democracia racial en Puerto Rico, la sexualización de ciertos valores sociales como rasgos definidores de la cultura afropuertorriqueña, como señala en Narciso descubre su trasero (1975), es una clara manifestación de la virulenta discriminación racial y social que persiste en la cultura puertorriqueña (Tomo II, 125). Aunque Zenón, en su referencia a la obra de Luis Rafael Sánchez, se limita a comentar brevemente sobre "Tiene la noche una raíz" y “¡Jum!”, pasa por alto la alabanza a la hipersexualidad en la cual queda ensalzado el erotismo de los personajes en el cuento "Aleluya negra" (Barradas 55-63). Para Luis Rafael Sánchez, 
la matriz erótica se transforma en la táctica narrativa que expande la significación ideológica de su proyecto narrativo posterior. Por ejemplo, en La Guaracha del Macho Camacho (1976) la perversión sexual equipara una proyección de las diferentes dimensiones sociales que abarcan los personajes en la paradoja del colonialismo. Sin embargo, esos aspectos psicosomáticos y sexuales restringen la clasificación racial al producto de una esencia biológica, según lo analiza Zenón como sujeto y objeto del discurso racial, reduciendo así las representaciones de la personalidad negra a un mimetismo clausurado en el primitivismo, el erotismo y la irracionalidad sexual.

Ahora bien, la psicología unidimensional que el exotismo había estipulado a la subjetividad negra gana un nuevo ímpetu con los reclamos del movimiento feminista. La reivindicación del mundo femenino intercala la opresión racial en el mundo narrativo, para denunciar solidariamente la exclusión que comparten ambos grupos dentro de la jerarquía social y económica. La cuentística de Rosario Ferré logra entretejer el conflicto racial a los conflictos de clase y género con una intención emancipadora. Pero la operación estética de ese gesto depende de la contingencia de la cultura afropuertorriqueña demarcada a un espacio social limitado, y a su vez subvencionado por un exotismo carnal y escatológico. En el cuento, "Cuando las mujeres quieren a los hombres" (1976), la idealización erótica de la mujer negra ventila el deseo de desmantelar las normas culturales y sociales que rigen la vida de la mujer criolla dentro del orden social burgués. El maniqueísmo narrativo convierte el espacio social que ocupa el cuerpo subordinado racial, sexual y moralmente de Isabel la Negra en la fantasía de Isabel Luberza.

Para Isabel Luberza la narrativa mantiene formalidad retórica ("Isabel Luberza la Católica", "la dama popular", "la santa de las Oblatas" [25]), mientras que para Isabel la Negra intertextualiza el exotismo del personaje palesiano del poema "Majestad Negra" ("Isabel la Rumba Macumba Candombe Bámbula; Isabel la Tembandumba de la Quimbamba" [25]). La exterioridad temática y figurativa, con la que se recrea la experiencia de la mujer negra, es otra manera de duplicar las exclusiones que se llevan a cabo al margen del orden simbólico masculino y racial. Asimismo, ese intercambio de lugares sociales reflejados en la imagen de sus cuerpos problematiza la autoridad política que asume la artificialidad de los cuerpos diferenciados racial y sexualmente, ya que el cuerpo negro pasa a desempeñar las funciones físicas y privadas que no ejerce el cuerpo blanco que representa la razón (Butler 49). En ese sentido, el cuerpo negro de Isabel la Negra es desmaterializado por Isabel Luberza para contextualizar sus deseos de liberación. ${ }^{7}$ Aunque, como observa Frances Aparicio, la fusión psíquica y simbólica de los cuerpos al final del cuento "se podría tildar de una fácil apología del mestizaje — en este caso mulatismo- que indica un rechazo de la historia oficial que dualiza la realidad en términos maniqueístas, en blanco(s) y negro(s), y que define la identidad nacional puertorriqueña en base a lo blanco y europeo" (78). A pesar de eso, la evocación de la cultura negra y la denuncia de la situación de la mujer entra en conflicto ideológicamente con la intencionalidad antillanista del proyecto literario de Ferré. La articulación de la existencia negra colapsa en el circuito cultural que forja la poesía

\footnotetext{
${ }^{7}$ Según Juan Gelpí, en el encuentro entre Isabel Luberza e Isabel La Negra "hay un placer en el descubrimiento del cuerpo de esa otra" (161) que contradice la posibilidad de un enfrentamiento violento.
} 
negroide iniciada por Palés, desestimando el espectro político radical hacia el cual se aproxima el conflicto racial a nivel local y mundial conjuntamente con las luchas de liberación sexual. ${ }^{8}$

Pese al optimismo con el cual la producción cultural e intelectual de los años sesenta y setenta prefigura la configuración racial de la personalidad nacional en el ambiente literario, la organización política e histórica del cuerpo negro sigue distanciada de las disposiciones pragmáticas que generan sus condiciones sociales en el orden simbólico (Bourdieu 73) de la política colonial puertorriqueña. La falta de reconocimiento de esquemas y percepciones que organicen los aspectos más íntimos de la vivencia negra ponen en evidencia contradicciones que cancelan la unidad del imaginario nacional. No obstante, cuando José Luis González publica su ensayo "El país de cuatro pisos" en 1980, es un momento clave en el que se recupera con optimismo la vitalidad cultural y el potencial político de las masas populares. A pesar de que el afroantillanismo de González sigue subordinado a los matices fenomenológicos de la cultura negroide, el acercamiento marxista al argumento racial, se desdobla políticamente en un revisionismo histórico que consolida en la africanía cultural, la oposición más resistente para trastocar los intereses de la clase dominante y combatir la política de americanización. Sin embargo, en la producción literaria de los años ochenta y noventa, la existencia racial no queda restringida exclusivamente a las contradicciones del progreso industrial y tecnológico, sino también a ese momento espiritual de disidencia intelectual e imaginativa en el cual se rechaza la intromisión de fuerzas políticas y legales que buscan negar la subjetividad, el lenguaje y la historia de un pueblo agredido por el colonialismo.

\section{REMEMBRANDO EL CUERPO NEGRO}

Sin duda alguna, la participación femenina sobresale en la literatura puertorriqueña por la originalidad y la creatividad con que la metáfora del cuerpo ha sido manejada en la contextualización histórica de la lucha anticolonial. En la ficción, el proceso de reflexidad entre raza como cuerpo y raza como metáfora de la nación, establece el balance entre el lenguaje figurativo y el lenguaje literal, que mediante la interdependencia racial y sexual, pone en escena las vicisitudes de la realidad nacional. El énfasis en la evidencia física es el recurso narrativo que reorganiza la memoria racial y sexual que ha quedado obliterada en la historia oficial. En los cuentos de Ana Lydia Vega y Mayra Santos Febres, la contigüidad con ese pasado fragmentado y disipado propicia la autodeterminación de participar como sujeto y objeto dentro de la historia cultural y nacional.

\footnotetext{
${ }^{8}$ En el ensayo, "AfroPuerto Rican Cultural Studies: Beyond cultura negroide and antillanismo", (Centro 8/1\&2; 57-77), Juan Giusti identifica una contradicción similar en la obra de Edgardo Rodriguez Juliá. "While Rodríguez Juliá's genuine interest in history, and its connections with contemporary reality, has broken new ground in Puerto Rican literature, his approaches to AfroPuerto Rican history does not sufficiently register complexity and ambiguity. Rodriguez Juliá too quickly accepts stark dichotomies - highlands vs. coast, black-mulatto vs. jibaro, peasant vs. proletarian, rural vs. urban- for Puerto Rican history, sharply distinct worlds populated since the nineteenth century by white highland peasants and black coastal proletarians. More generally, Rodríguez Juliá casts AfroPuerto Ricans as slaves, rebels or maroons" (67).
} 
En el caso particular de Ana Lydia Vega, el relato "Pollito Chicken", que aparece en su publicación junto a Carmen Lugo Filippi de Vírgenes y mártires (1981), intertextualiza la metáfora de la "mulata-antilla" palesiana no como "un emblema unificador y abstracto" de la identidad antillana, "sino [como] un ser histórico y concreto" (González 296) que concilia la lucha de autodefinición nacional con la lucha contra la discriminación racial y sexual. La manipulación y el control de los símbolos culturales ocupan el espacio político real del imperialismo racial que obstruye la solidaridad política entre los miembros de la diáspora africana. En los Estados Unidos esa dualidad del conflicto racial surge en Suzie como el rechazo de "los negros — que no eran mejores que los New York Puerto Ricans pero por lo menos no eran New York Puerto Ricans" (75-76). En Puerto Rico se refuerza en la tradición heredada de la abuela que se opuso al matrimonio de su madre y su padre porque según la abuela él "tenía el pelo kinky" (76). Los principios estéticos que enmarcan la simultaneidad entre el sufrimiento y el poder, la marginación y la amenaza, la sumisión y el narcisismo, informan el proceso de la ficción como un movimiento fluido y flexible en el cual la caracterización de Suzie Bermúdez se convierte en la iconografía de la condición cultural del colonizado.

De hecho, el cuerpo de Suzie Bermúdez es el "texto" donde la experiencia de la colonización ha escrito los mensajes más gráficos sobre el conflicto de resistencia y opresión. En este relato la anatomía imaginaria de Suzie Bermiúdez simboliza una doble negatividad que se vuelve la tabula rasa en la cual puede reinscribirse positivamente la identidad sexual y racial del colectivo nacional. Al momento de reconciliar su cuerpo y su mente en la relocalización geográfica y social, redescubre una identidad que explora, reta y desestabiliza la interpretación de su historia cultural. EI nuevo espacio crítico que produce la identificación cultural y política de Suzie Bermiúdez eleva la relación física al instante lingüístico de reinventar y revolucionar la construcción de la realidad nacional. Así pues, en el mundo narrativo de Vega el cuerpo devaluado y marginado de la mulata reapropia la capacidad transgresiva de la sexualidad para reclamar su lugar en el centro del dilema colonial. Por eso al final del cuento, cuando Suzie Bermiúdez invoca la liberación de la patria colonizada, en medio del orgasmo intrauterino con el bartender negro de la piscina, la condición de los cuerpos colonizados invierten su función redentora usual.

El placer orgásmico de la protagonista libera la identidad femenina y el lenguaje de las normas culturales y sociales establecidas por el control masculino. El deseo y el placer sexual tienen el poder de elevar el subconciente de Suzie al nivel de la razón y la lógica del discurso nacional. Ella comunica desde el subconciente un lenguaje dominado por el impulso, la disposición y el sentimiento de la pasión que se conecta al cuerpo femenino. El lenguaje del subconsciente efectúa una inversión de los valores femeninos asociados a la carnalidad y la sexualidad corrosiva de la mulata para asumir un estatus de superioridad política. En ese sentido, el esencialismo biológico de la mulata transforma irónicamente la metáfora de la "mulata-antilla" en una de gran envergadura social y política. La experiencia erótica brinda el poder de emitir una voz que se regocija en un nuevo lenguaje que imparte la energía creativa para combatir, en el sentido estético y ético, cualquier tipo de opresión. ${ }^{\text {' }}$

\footnotetext{
"Sobre la revitalización democrática de lo erótico, Anthony Giddens sostiene que: "El erotismo es la sexualidad reintegrada en una gama amplia de objetivos emocionales, entre los que la comunicación es el supremo. Desde el punto de vista del realismo utópico, el erotismo resulta del triunfo de la voluntad que, desde Sade hasta Bataille, parece afirmarse" (182).
} 
Asimismo, la imagen y la voz de la mulata producen un lenguaje que reorganiza los aspectos fragmentados de una existencia política que se proyecta hacia el futuro de la lucha nacional. El erotismo que conforma el proceso de la ficción permite que Suzie Bermiúdez denuncie la opresión colonial mediante el yo público que asume su caracterización.

En cambio, en el mundo narrativo de Mayra Santos Febres, el erotismo apela al deseo utópico de un yo privado que idealiza un momento de igualdad, reconocimiento y respeto para la mujer negra. La inscripción textual de la intimidad y la corporeidad aromática de Marina París en el cuento, "Marina y su olor", de la colección de cuentos Pez de vidrio (1995), captura una otredad racial concreta. Este relato crea la apertura de un medio comunicativo mediante el cual los estigmas históricos asociados a la explotación y la opresión sexual de la mujer negra, desdoblan en la exploración de un sentido de identidad propio y en la recuperación imaginaria de una historia individual. El poder de controlar los aromas que expulsa su cuerpo efectúa una transformación consciente de las instancias residuales del pasado esclavista. La reflexión de Marina se describe así:

Después de sentirse complacida con los resultados de sus experimentos aromáticos caseros, Marina empezó a experimentar con los olores sentimentales. Un día trató de imaginarse el olor de la tristeza. Pensó firmemente en los Velázquez. Pensó en don Esteban, su papá, sentado allí imaginando lo que pudo haber sido su futuro como clarinetista en las bandas de mambo o en las pachangas de César Concepción. En seguida del cuerpo le salió un olor a mangle mañanero y a calor de sábana así entre rancio y medio dulzón. Después de esto, practicó los olores de la soledad y del deseo. Aunque pudo sacar aquellos aromas de su propio cuerpo, el ejercicio la dejaba exhausta: le causaba demasiado trabajo. Así fue que Marina empezó a recoger olores de los patrones, de los vecinos de la casona Velázquez, de la servidumbre que vivía en los cuartitos del patio junto a las gallinas y los hilos de tender la ropa interior del hijo de doña Georgina (46).

La reordenación de esas imágenes aromáticas que permanecían desmembradas, sin una forma, secuencia o significado en la memoria de Marina, dramatizan la toma de conciencia de un discurso histórico propio. Así como Sethe, la protagonista de la novela Beloved (1987) de Toni Morrison, el personaje de Santos Febres complementa la interioridad y la exterioridad de una memoria racial que logra remembrar en la metáfora del cuerpo de Marina, la conexión del pensamiento y la memoria como la inscripción material de un pasado histórico que augura la renovación del presente y del futuro (Henderson 66-67). La transgresión discursiva del relato historiza la ficción y ficcionaliza la historia del período de transición de los negros libres a la sociedad civil en el contexto del "creciente pueblo de Carolina" (43).

Por otra parte, la exploración de la interioridad de Marina renueva el trabajo sobre los códigos lingüísticos, revelando la construcción cultural del racismo en la sociedad puertorriqueña, que se acuña en el lenguaje popular en dichos como el de "los negros apestan". Esas palabras son los insultos desmoralizantes que utiliza doña Georgina para prohibir el amor de Marina y de Eladio Salamán: "¡Mala mujer, indecente, negra apestosa, apestosa!" (48). Aquí el lenguaje provee un marco de referencia para la interpretación y la referencialidad de la conducta adversa de la mujer negra en el contexto social. El sobresalto moral que experimenta doña Georgina ante la supuesta irregularidad sexual de Marina, hace 
que la patrona se sienta autorizada por el poder que le garantiza su posición económica y social, a imponer límites y controles a la conducta de Marina. Doña Georgina identifica en el comportamiento de Marina un problema social, un problema que tiene que ser rectificado para restaurar el orden moral y social que dictaminan las normas de su clase. Asimismo, las palabras de doña Georgina encubren verdades históricas que abren las "cicatrices" remanentes de los horrores de la esclavitud en el cuerpo de Marina (Homans 89). Por eso, al final del cuento, cuando ya "no pudo controlar su cuerpo" (50) del hostigamiento sexual de Hipólito Velázquez, expulsa los olores de la destrucción. Después de derrumbar a Hipólito con olores de aceite quemado y ácido de limpiar turbinas, ella fumiga la casa de la patrona con olores de "sueños muertos" (50) y "aromas inconexos, desligados" (50) que condenan a los Velázquez a convertirse en una familia venida a menos en la historia del pueblo. Finalmente, la reivindicación de su libertad se reitera en las "palabras hediondas" (50) que pronuncia antes de regresar con Eladio y su familia: “¡Para que ahora digan que los negros apestan!" (50). Así es como el proyecto literario de Mayra Santos Febres invierte la fatalidad de un cuerpo marcado históricamente para reconocerle el potencial de una fortaleza interna que determina su propio destino.

El poder de la memoria olfativa de Marina reafirma un acto de "cimarronaje psíquico" (Dash 334) que devuelve el elemento humano al mito de la hipersexualidad de la negra mediante la imaginación y la fantasía. La función corporal deconstruye simbólicamente la memoria racial de la subordinación, inscrita en el cuerpo negro debido al utilitarismo material fundamentado en la historia de la esclavitud. La caracterización de Marina reapropia la genealogía literaria del cuerpo seductor y erótico de la negra para exponer una nueva articulación de las nociones de tiempo, espacio, belleza y poder. El erotismo de la palabra propicia el estado utópico para enunciar el ideal de una voz interior que dé testimonio de la lucha moral y física encarada por la población negra en Puerto Rico. De ese modo la cuentística de Mayra Santos Febres modifica las convenciones literarias asociadas a la identidad negra, ya que resucita una contranarrativa del legado esclavista, y propone un nuevo paradigma racial en la interpretación de las relaciones culturales y políticas en Puerto Rico.

\section{Conclusión}

El ciclo de la reciprocidad histórica entre el ideal nacional y la represión racial orientan un esfuerzo progresivo de exteriorizar o de interiorizar las pautas ideológicas de la misión hegemónica en la política puertorriqueña. En ese proceso recurrente, las manifestaciones culturales y sociales mantienen una disyuntiva constante entre las fuerzas sociales y las tradiciones intelectuales. En la literatura, el determinismo cultural al que se ha circunscrito el lenguaje literario centraliza la identidad racial, la resistencia cultural y la rebelión política en la alusión de una subjetividad nacional dislocada de su nexo temporal en el espacio político. La fase generativa de ese reclamo ideológico se adscribe a un biologismo racial que activa la sexualización de ciertos valores sociales: la energía, la iniciativa, las representaciones viriles de la dominación, o el opuesto: la pasividad, la sensualidad o la femeneidad. Dentro de esa coyuntura, las expresiones corporales y psicológicas del carácter nacional privilegian los valores de la esfera privada como parte del espectro político. La 
intromisión en ese espacio intimo, muchas veces denuncia la monstruosidad de la opresión, y en esa discusión, las constricciones de la ontología racial complementan la enunciación de voces subversivas que contradicen la opresión individual para identificarse con las esperanzas y los cambios al nivel colectivo.

La trayectoria de las estrategias narrativas que se advierte desde Luis Palés Matos hasta Mayra Santos Febres demuestra el aspecto subliminal y trascendental al cual ha aspirado el nacionalismo cultural mediante la manipulación estética del cuerpo negro. Las concepciones metafísicas a las que aluden los símbolos, las metáforas y las representaciones expresadas por el cuerpo negro, materializan un "super nacionalismo" (Balibar 59) que anhela censurar la conexión entre el racismo, la explotación y la alienación política. En la ficción, el reordenamiento simbólico de la realidad ambiciona redimir la memoria racial inscrita en la historia cultural del cuerpo negro, para así articular una unidad temporal de la superioridad moral y heroica que conlleva la lucha descolonizadora. Sin embargo, el significado social de la categoría racial resulta inestable en la centralización de los proyectos culturales y políticos, ya que son registros retóricos que se crean, se transforman y se destruyen para simbolizar conflictos e intereses particulares en momentos determinados de la historia. La incongruencia racial en el ambiente cultural y político de Puerto Rico revela las constantes negociaciones que acompañan la identificación de la subjetividad negra en relación con otras subjetividades nacionales. El sentido de inautenticidad, desintegración y dispersión que ha tratado de imponerle la cultura oficial a la organización estética, política y social de la cultura negra mantiene una constante movilización conflictiva entre el deseo, el temor y el poder de representar la heterogeneidad nacional.

\section{OBRAS CITADAS}

Aparicio, Frances. "Entre la guaracha y el bolero: un ciclo de intertextos musicales en la nueva narrativa puertorriqueña". Revista Iberoamericana 162-163 (1993): 73-89.

Arce de Vázquez, Margot. Impresiones puertorriqueñas. San Juan de Puerto Rico: Editorial Yaurel, 1950.

Balibar, Etienne. "Racism and Nationalism". Race, Nation, Class: Ambiguous Identities. [1989]. E. Balibar \& E. Wallerstein, eds. Londres: Verso, 1991. 37-67.

Barradas, Efraín. Para leer en puertorriqueño: acercamiento a la obra de Luis Rafael Sánchez. Río Piedras: Editorial Cultural, Inc., 1981.

Benítez, Jaime. "Luis Palés Matos y el pesimismo en Puerto Rico: doce años después". Tuntún de pasa y grifería. San Juan: Biblioteca de Autores Puertorriqueños, 1950. 941.

Tuntún de pasa y grifería. Luce López-Baralt, ed. San Juan: Instituto de Cultura Puertorriqueña y Editorial Universidad de Puerto Rico, 1993. 166-192.

Bourdieu, Pierre. The Logics of Practice. California: Stanford University Press, 1990. Butler, Judith. Bodies that Matter: on the Discursive Limits of 'Sex'. Nueva York: Routledge, 1993.

Cachán, Manuel. “'En cuerpo de camisa' de Luis Rafael Sánchez: la antiliteratura alegórica del otro puertorriqueño". Revista Iberoamericana 162-163 (1993): 175-186. 
Dash, Michael. "In Search of the Lost Body: Redifining the Subject in Caribbean Literature". The Post-Colonial Studies Reader. B. Aschcroft, G. Griffiths \& H. Tiffin, eds. Londres: Routledge, 1995. 332-335

Díaz Quiñones, Arcadio. "La poesía negra de Luis Palés Matós: realidad y conciencia de su dimensión colectiva”. El almuerzo en la hierba. Río Piedras: Ediciones Huracán, 1982. 73-97.

Ferré, Rosario. Papeles de Pandora. [1976]. Río Piedras, 1991.

García Canclini, Néstor. "Cultural Reconversion". On Edge: The Crisis of Contemporary Latin American Cultures. George Yúdice, Jean Franco \& J. Flores, eds. Minneapolis: Univesity of Minnesota Press, 1996.

Gatens, Moira. Imaginary Bodies: Ethic, Power and Corporeality. Londres: Routledge, 1996.

Gelpí, Juan G. Literatura y paternalismo en Puerto Rico. Río Piedras: Editorial de la Universidad de Puerto Rico, 1993.

Giddens, Anthony. La transformación de la intimidad: sexualidad, amor y erotismo en las sociedades modernas. B. Herrero Amaro, trad. Madrid: Ediciones Cátedra, S.A., 1998.

Gikandi, Simon. Writing in Limbo: Modernism and Caribbean Literature. Ithaca: Cornell University, 1992.

Giusti Cordero, Juan A. “AfroPuerto Rican Cultural Studies: Beyond cultura negroide and antillanismo". Centro 8/1\&2 (1996): 57-77.

González, José Luis. El país de cuatro pisos y otros ensayos. Río Piedras: Ediciones Huracán, 1980.

González, Aníbal. "Ana Lydia Pluravega: unidad y multiplicidad caribeñas en la obra de Ana Lydia Vega”. Revista Iberoamericana 162-163 (1993): 289-300.

Grosz, Elizabeth. Volatile Bodies: Toward a Corporeal Feminism. Bloomington: Indiana University Press, 1994.

Henderson, Mae G. "Toni Morrison's Beloved: Re-Membering the Body as Historical Text". Comparative American Identities: Race, Sex and Nationality in the Modern Text. H. J. Spillers, ed. Nueva York: Routledge, 1991. 62-86.

Homans, Margaret. "'Racial Composition': Methaphor and the Body in the Writing of Race". Female Subjects in Black and White: Race Psychoanalysis, Feminism. E. Abel, B. Christina \& H. Moglen, eds. California: University of California Press, 1997. 77101.

Lugo-Ortiz, Agnes. "Community at Its Limits: Orality, Law, Silence and the Homosexual Body in Luis Rafael Sánchez ¡Jum!”. ¿Entiendes?: Queer Readings, Hispanic Writings. E. Bergmann \& P. J. Smith, eds. Durham: Duke University Press, 1995. 115-136.

Omi, Michael y H. Wintant. Racial Formation in the United States: From 1960s to the 1990s. Nueva York: Routledge, 1994.

Ríos Avila, Rubén. "La raza cómica: identidad y cuerpo en Pedreira y Palés". La Torre 7 (1993): 559-576.

Roy Fequiere, Magali. “'Negar lo negro sería gazmoñería': Luis Palés Matos, Margot Arce, and the Black Poetry Debate". Centro 8/1\&2 (1996): 82-91. 
Sánchez, Luis Rafael. En cuerpo de camisa. Río Piedras: Editorial Antillana, 1975. Santos Febres, Mayra. Pez de vidrio. [1995]. Río Piedras: Ediciones Huracán, 1996.

Vega, Ana Lydia. Vírgenes y martíres. Río Piedras: Editorial Antillana, 1988.

Winant, Howard. Racial Conditions: Politics, Theory, Comparisons. Minneapolis: University of Minnesota Press, 1994.

Zenón Cruz, Isabelo. Narciso descubre su trasero. Humacao: Furidi, 1975. 
